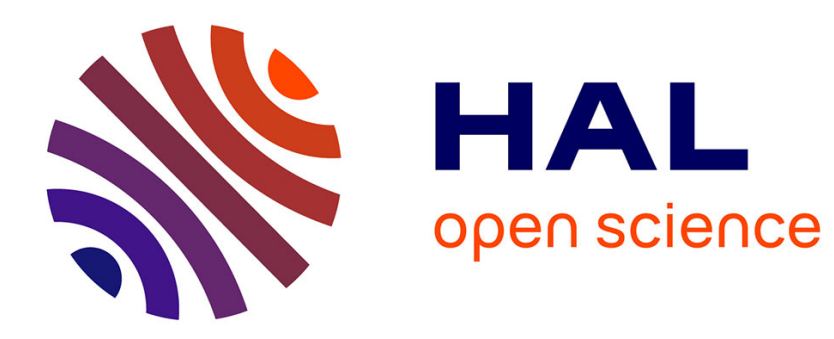

\title{
The dynamics of Environmentalism and the Environment
}

\author{
Ingmar Schumacher
}

\section{To cite this version:}

Ingmar Schumacher. The dynamics of Environmentalism and the Environment. 2009. hal-00392379

\section{HAL Id: hal-00392379 \\ https://hal.science/hal-00392379}

Preprint submitted on 7 Jun 2009

HAL is a multi-disciplinary open access archive for the deposit and dissemination of scientific research documents, whether they are published or not. The documents may come from teaching and research institutions in France or abroad, or from public or private research centers.
L'archive ouverte pluridisciplinaire HAL, est destinée au dépôt et à la diffusion de documents scientifiques de niveau recherche, publiés ou non, émanant des établissements d'enseignement et de recherche français ou étrangers, des laboratoires publics ou privés. 


\section{ECOLE POLYTECHNIQUE}

CENTRE NATIONAL DE LA RECHERCHE SCIENTIFIQUE

THE DYNAMICS OF ENVIRONMENTALISM AND THE ENVIRONMENT

Ingmar SCHUMACHER

June 2009

Cahier $n^{\circ} 2009-20$

\section{DEPARTEMENT D'ECONOMIE}

Route de Saclay

91128 PALAISEAU CEDEX

(33) 169333033

http://www.enseignement.polytechnique.fr/economie/

mailto:chantal.poujouly@polytechnique.edu 


\title{
THE DYNAMICS OF ENVIRONMENTALISM AND THE ENVIRONMENT
}

\author{
Ingmar SCHUMACHER ${ }^{1}$
}

June 2009

Cahier n 2009-20

\begin{abstract}
We study the relationship between environmental preferences and the environment. Preferences are transmitted intergenerationally and through social interactions, where we assume that agents are more likely to adopt environmental preferences the larger the amount of pollution. In the basic setting we find that both converge non-monotonically towards an interior steady state. When including technical change we notice that there will be no change in the steady state level of the environment unless technical change is sufficiently strong, which stands in stark contrast to the literature. Upon introducing environmental laws we find that these may lead to a virtually pollution-free environment. This happens if environmental laws are implemented when public support is strong enough.
\end{abstract}

\footnotetext{
${ }^{1}$ Department of Economics, Ecole Polytechnique, 91128 Palaiseau Cedex, France. email: ingmar.schumacher@polytechnique.edu. tel: 0033 169333038. The author kindly acknowledges the helpful comments by two anonymous referees.
} 


\section{Introduction}

In this article we study the endogenous evolution and dynamics of environmentalism. By environmentalism we mean a certain attitude towards the environment that translates into a green behavior. Our approach here is based on the recent literature of cultural dynamics, especially on two papers by Bisin and Verdier ([4], [5]). They derive cultural dynamics of preferences and norms through a transmission of social interactions across generations. We build upon their basic derivation of cultural dynamics but include a feedback from pollution ${ }^{1}$ to the cultural dynamics as well as a feedback from the resulting cultural attitudes to pollution. More precisely, we assume that pollution affects the proportion of the two cultural traits that exist - environmentalists (greens) and browns. Browns are not motivated by environmental norms and show a strongly polluting behavior, whereas environmentalists follow a social norm that reduces their impact on pollution. Within a very general setting we then study the interaction between the proportion of environmentalists and the amount of pollution. The key assumption behind our cultural dynamics is that green preferences are less likely to be transmitted intergenerationally for low levels of pollution, whereas they are likely to be transmitted for high levels of pollution ${ }^{2}$.

There are several articles which study social norms and their impact on the environment. A major contribution is Sethi and Somanathan [31], who study the endogenous evolution of social norms in a local common-property resource setting with three players: defectors, cooperators and enforcers. Their main finding is that two possible stable Nash-game equilibria may exist: an individualistic society with defectors only, or a norm-guided society with both cooperators and enforcers. Without a sufficiently large amount of enforcers, the individualistic society in Sethi and Somanathan [31] is the only stable equilibrium. Instead, we focus on a setting without enforcers, which makes most sense for global pollutants. ${ }^{3}$ Since our social

\footnotetext{
${ }^{1}$ We shall use pollution and environment interchangably where by pollution we simply mean a degraded state of the natural environment.

${ }^{2}$ For example, when looking at data for fisheries, we notice that many stocks of fishes were rather high during the 70s (see Larcombe and Begg [23]). Then during the 80s and 90s the percent of total fishery stocks that were at sustainable levels declined substantially to levels that were often unsustainable. Due to regulations and often coordination among fishers, in our terminology an increasing concern, the percent of fishery stocks that are overfished started to decline again during the last three years. Similar stories can found for local pollutants and waste management.

${ }^{3}$ This would also apply to common properties in urban areas where people do not know each other, for
} 
norms are furthermore transferred intergenerationally, we find that Sethi and Somanathan's result does not hold any longer, but we obtain an interior steady state. In this steady state environmentalists will co-exist with browns at a positive but stable level of pollution. This stable level of pollution is determined by the exogenous probability that is positively related with (but not identical to) becoming a brown and the strength with which pollution induces environmentalists. If even low levels of pollution increase the amount of environmentalists drastically then the steady state level of environmentalists is likely to be high and that of pollution low.

Brekke et al. [9] introduce the idea of morally ideal effort into a static Nash game of a public good. Their main finding is that allowing for moral sentiments still leads to an underprovision of public goods, and public policy in terms of a fee might reduce the morally ideal effort. In comparison, since we are interested in the dynamic interaction between social norms and the environment, we do not fully study the individual's effort level. Our analysis obtains therefore a more descriptive touch and should be understood as such.

Nyborg et al. [26] study a similar setup as Brekke et al. [9] and introduce a dynamic dimension through replicator dynamics (see Taylor and Jonker [32]). They find that two equilibria are socially stable, one being everyone acting green and the other being everyone acting brown. ${ }^{4}$ They then study the effect of taxes and find that this could shift everyone towards the green equilibrium. Their result comes about since they assume that moral motivation to act green is strong if many people act green, whereas moral motivation is low if few people act green. Our approach does not involve the intrinsic moral motivation of a person but instead focuses on a social norm that is being adopted by society. Freely interpreted, one can say that this social norm penetrates deeper into society the larger the need for social action. As a result, we do not find two extreme equilibria like Nyborg et al [26] but a stable interior one.

Buenstorf and Cordes [11] study the evolution of norms given that three types of social behavior exist. They do not study the interaction of these types with the environment and assume that the proportion of preference types changes with fixed weights associated to each type and a fixed bias parameter. Though we only focus on two types, we introduce a feedback from the endogenous social norms to the environment and vice versa. We show that this endogenous dependency leads to crucial differences.

pollutants with atomistic agents, or for high private costs of becoming an enforcer.

${ }^{4}$ This result therefore confirms Sethi and Somanathan's work when one excludes enforcers. 
We furthermore investigate the extent to which technical change and environmental laws impact the relationship between environmentalism and the environment. Including a standard form of pollution-saving technical change, we find that this may not lead to any change in the steady state pollution level. The only way in which the steady state pollution level will be affected is if human behavior can be sufficiently decoupled from the changes it induces to pollution. This stands in stark contrast to the results in the current literature, where the type of technical change that we introduce here leads to smooth and continuous reductions in pollution. Finally, environmental laws and standards may lead to a virtually pollution-free environment. This happens if laws are implemented when the public support is sufficiently strong.

The article is organized as follows. Section 2 motivates the approach undertaken here. Section 3.1 introduces the basic model and discusses some results. Section 3.2 introduces technical change and some of its possible implications. Section 3.3 discusses the impact of environmental laws and standards. Finally, section 4 concludes.

\section{Some motivations}

In his 1940 book (reprint 1963) Linton describes culture as "the sum total of the knowledge, attitudes and habitual behavior patterns shared and transmitted by the members of a particular society... Cultures are adaptive mechanisms and as such represent a response to the needs of our species" ([24], p.466). "Culture change is, at bottom, a matter of change in the knowledge, attitudes and habits of the individuals who compose a society" ([24], p.468). Therefore, culture and the resulting behaviors are non-stationary results of an ongoing process of interaction and local structures. For example, on the specific topic of Linton's [24] anthropological edited volume, the native Indians in the US were very much at peace with nature until the Europeans started to intervene. Now, fewer native Indians try to preserve their traditional way of life. More generally, one can hardly comprehend the range of changes the industrial revolution has brought about in terms of lifestyle and behavior. Mankind is now, for the most part, living a life that is becoming more and more detached from the classical turns of nature. We do not anymore need to follow the rhythm of the earth when organizing our activities. Instead, we switch the light on when it gets dark, turn the heater on when it gets cold, and eat vegetables that have been grown on the other side of the planet 
when the local season does not allow for it. People become much less dependent on their close neighbors and local systems but instead interact with others all over the globe. These new possibilities also shape our preferences and attitudes in new directions ${ }^{5}$.

Thus, preferences must be viewed as a fluid concept which might easily change and adapt over space and time. We are not simply born in a world with a given set of preferences. One's attitude and behavior clearly evolve according to the type of preferences that one is exposed to. On the one hand, we know that parents' attitudes and the preferences of one's social relations disproportionately affect the preferences that children will adopt (Dalhouse and Frideres [14], Graumann and Kruse [17], Villacorta et al. [36]). On the other hand, these preferences are very often also shaped out of the urgent need to act in a certain way. For example, 'saving the whales' became a wide-spread attitude only after the whales were in danger of extinction. ${ }^{6}$ If one accepts that preferences may change, then revealed preferences provide a good description of the attitudes underlying a specific choice only under the specific lab condition during that choice. ${ }^{7}$ Clearly, one therefore has to search for the fundamental forces that drive decisions, namely the decision-takers' attitudes.

Given that economists have strongly focused on the static utility function, it is no wonder that this allowed a head start for other disciplines, mainly sociologists and political scientists. The main conclusion from a review of the sociological literature seems to be that environmental behavior comes from different attitudes towards the degree of egalitarianism and social forces, as well as from the way agents are affected by the environment. For example, environmentalists are generally found to be the type of people who are also more concerned about an egalitarian distribution and who are thus more willing to make personal sacrifices

\footnotetext{
${ }^{5}$ For example, there has been a significant trend towards individual autonomy and increased acceptance of divorce as well as unmarried cohabitation in the US during the past decades (see e.g. Thornton and Young-DeMarco [33]).

${ }^{6}$ Preferences are different across individuals, families, social groups, regions and countries and also over time. The static concept of preferences in economics is clearly having trouble holding up in practice, and a multitude of sociological and psychological research shows exactly why. The economic literature is steadily picking up on this idea of the endogeneity of preferences. Prominent examples are the effect on the preferences from an endogeneity of the discount rate (Becker and Mulligan [2]), from religious or group characteristics (Escriche et al. [16]), and through an evolutionary selection and the importance of cultural traits (Bisin and Verdier [4]; Bowles, [8]; Hauk [19]).

${ }^{7}$ For example, if one were to allow for a broadening of the initial choice set, then the revealed preferences may change, which is inconsistent with standard consumer choice theory. See, e.g., Sen [30].
} 
for the greater good (Kempton et al. [21], Schultz [29]). Whereas most US Americans believe that markets and capitalism are able to solve the environmental problems, environmentalists generally do not trust that this is the case. Ellis and Thompson [15] conclude that while both environmentalists and the general public have a strong preference towards clean air and a good environment, they differ in their level of activity due to their cultural differences in the way they organize their social and political way of life. Others, like Urban [35], find that environmental behavior is influenced by the level of pollution and the extent to which society offers participation in environmental projects. Olli et al. [27] conclude in a general population study in Norway that the social network is a significant driver of environmental behavior. Johnson et al. [20], using US national-level data, find that gender, age, and political orientation explain both environmental concern and behavior (see also Bord and O'Connor [6], Torgler and García-Valiñas[34], Brown and Taylor [10], Witzke and Urfei [38]).

Indeed, most of these attitudes are shaped to a considerable degree - if not exclusively by social interactions and relations. In my way of acting I am comparing myself to my family, to my neighbor, my classmates, my political and social figure heads. For example, Dalhouse and Frideres [14] find that upon questioning parents and their children in Canada that the political position of the parents is an important driver of their children's political position. Graumann and Kruse [17] find that awareness and attitudes are socially constructed, which implies that social relations play an important role in the formation of attitudes and values. In a similar vein, Villacorta et al. [36] show that parents' own environmental self-regulation influences their children's self-regulation.

We can therefore conclude that environmental attitudes and behaviors are deeply characterized by cultural aspects and that these cultural aspects are generally transmitted intergenerationally. Furthermore, attitudes and the resulting behavior develop endogenously through a cultural change that might be driven by technological evolutions, by exogenous cultural inflows or by the urgent need to adapt to specific circumstances.

\section{The model}

In this section we introduce the fundamental relationship between environmentalism, or in other words the environmental cultural dynamics, and the environment. We then study the impact of technical change and the implementation of environmental standards. Each 
subsection is followed by a short discussion of the potential implications for the general lessons that one can draw from this analysis.

\subsection{The fundamental relationship}

The basic setup of dynamic preferences is borrowed from Bisin and Verdier [4], [5]. However, here we allow for an interaction with the state of the environment for the reasons that we forwarded in the previous section. There exist two preference traits, labeled 'brown' and 'green'. Agents with a brown preference ${ }^{8}$ do not care about the environment at all and environmentalists follow the social norm by reducing their impact on the environment. This assumption allows us to study the basic idea without having to introduce an explicit choice mechanism, which thus leads to a simple system with clear results. ${ }^{9}$ We then assume that preferences extend over a line with $q(t) \in[0,1]$, where $q(t)=0$ implies completely brown preferences and $q(t)=1$ implies green preferences. Children are born into the world void of any set of preferences and are then exposed to either of the two preference traits and adopt one of these. A child born by green (resp. brown) parents becomes an environmentalist (resp. brown) with a probability $\tau$ (resp. $\bar{\tau}$ ) and with a probability $1-\tau($ resp. $1-\bar{\tau}$ ) is influenced by someone else from either of the two preference traits and subsequently adopts one of those preference traits. We assume that the probability $\tau$ is an endogenous function of the level of the environment, such that $\tau(P(t))$. On the other hand, $\bar{\tau}$ denotes the exogenously given probability of adopting the brown preferences from one's brown parents. Given that $q(t)$ designates the proportion of green preference traits in the society we can then derive the probability $p^{i j}(t)$, for $i \in\{g, b\}$, that a parent of trait $i$ has a child of preference trait $j$ as

$$
\begin{aligned}
p^{g g}(t) & =\tau(P(t))+(1-\tau(P(t))) q(t), \\
p^{g b}(t) & =(1-\tau(P(t))(1-q(t)), \\
p^{b b}(t) & =(1-\bar{\tau})(1-q(t))+\bar{\tau}, \\
p^{b g}(t) & =(1-\bar{\tau}) q(t) .
\end{aligned}
$$

\footnotetext{
${ }^{8}$ For generality one can assume that brown preferences designate any other reasonable, but mainly environmentally ignorant, preference type.

${ }^{9} \mathrm{~A}$ possible choice mechanism is provided in the appendix.
} 
The dynamics of these equations are then given by

$$
\begin{aligned}
q(t+1) & =p^{g g} q(t)+p^{b g}(1-q(t)) \\
& =q(t)+q(t)(\tau(P(t))-\bar{\tau})(1-q(t)) .
\end{aligned}
$$

The continuous time dynamic system of equation (6) together with a general environmental constraint is therefore

$$
\begin{aligned}
\dot{q}(t) & =q(t)(1-q(t))(\tau(P(t))-\bar{\tau}), \\
\dot{P}(t) & =f(P(t), q(t)) .
\end{aligned}
$$

Our assumptions on $\tau(\cdot)$ and $f(\cdot, \cdot)$ will be minimalistic since we would like to keep the results as general as possible.

Assumption $1 \tau(P(t)) \in[0,1], \tau^{\prime}(P(t)) \geq 0, \lim _{P \rightarrow 0} \tau(P)=0, \lim _{P \rightarrow \infty} \tau(P)=1$.

This implies that if pollution is low, then the probability that society adopts environmental preferences is very low. On the contrary, if pollution is sufficiently large, then people care more about the environment, start acting more environmentally friendly and society moves towards a structure of preferences where cultural attitudes include environmental objectives. For convenience we assume that the function is smooth and monotonic.

Assumption $2 f(P, q) \geq 0, f_{P} \leq 0, f_{P P} \geq 0, f_{q} \leq 0, f_{q q} \geq 0, P \in[0, \infty)$. Furthermore, (1) $\lim _{q \rightarrow 0} f(P, q)>0$ and $\lim _{q \rightarrow 1} f(P, q)<0$. Also, $(2) d q /\left.d P\right|_{\dot{P}=0}<0$.

The conditions imposed on the accumulation of pollution entail that pollution has its own regeneration mechanism $\left(f_{P}<0\right)$ and is bounded below by its natural state 0 but may increase to infinity. Condition (1) says that if no one has preferences which are directed towards the environment then pollution always increases. On the other hand, if everyone behaves environmentally friendly, then pollution always decreases. Condition (2) effectively excludes the possibility of inertia, irreversibilities or thresholds ${ }^{10}$. It states that a high steady state level of pollution is associated with a low level of environmentalists, whereas a low steady state level of pollution requires a lot of environmentalists.

We now analyze the basic dynamics that derive from this interrelationship between environmentalism and the environment. ${ }^{11}$

\footnotetext{
${ }^{10}$ These possibilities could be useful to study, but are not the focus of this article.

${ }^{11}$ We remind that both differential equations consist of stock variables and therefore stability of steady states requires two negative eigenvalues.
} 
Proposition 1 The dynamic system (7) and (8) has three steady states $\left(P_{1}, q_{1}\right)=(0,1)$, $\left(P_{2}, q_{2}\right)>0$ and $\left(P_{3}, q_{3}\right)=(\infty, 0)$. Both $\left(P_{1}, q_{1}\right)$ and $\left(P_{3}, q_{3}\right)$ are unstable and $\left(P_{2}, q_{2}\right)$ is either asymptotically stable or has converging, cyclical dynamics.

Proof 1 The Jacobian of the dynamic system (7) and (8) close to $\left(P_{1}, q_{1}\right)$ is given by

$$
\left.\mathcal{J}\right|_{\left(P_{1}, q_{1}\right)}=\left[\begin{array}{cc}
\bar{\tau} & 0 \\
f_{q}(0,1) & f_{P}(0,1)
\end{array}\right] .
$$

The two eigenvalues $\lambda_{11,12}$ of this dynamic system are therefore given by $\lambda_{11}=\bar{\tau}>0$ and $\lambda_{12}=f_{P}(0,1)<0$. Therefore, the steady state $\left(P_{1}, q_{1}\right)$ is instable.

The Jacobian around $\left(P_{2}, q_{2}\right)$ is given by

$$
\left.\mathcal{J}\right|_{\left(P_{2}, q_{2}\right)}=\left[\begin{array}{cc}
0 & q_{2}\left(1-q_{2}\right) \tau^{\prime}\left(P_{2}\right) \\
f_{q}\left(P_{2}, q_{2}\right) & f_{P}\left(P_{2}, q_{2}\right)
\end{array}\right] .
$$

The eigenvalues associated with this equilibrium point are $\lambda_{21,22}$ and given by

$$
\lambda_{21,22}=\frac{f_{P}\left(P_{2}, q_{2}\right) \pm \sqrt{f_{P}\left(P_{2}, q_{2}\right)^{2}+4 f_{q}\left(P_{2}, q_{2}\right) q_{2}\left(1-q_{2}\right) \tau^{\prime}\left(P_{2}\right)}}{2} .
$$

Since $\Delta=f_{P}\left(P_{2}, q_{2}\right)^{2}+4 f_{q}\left(P_{2}, q_{2}\right) q_{2}\left(1-q_{2}\right) \tau^{\prime}\left(P_{2}\right) \gtrless 0$ we may have either complex dynamics (if $\Delta<0$ ) or asymptotic stability (if $\Delta>0$ ). The trajectory $\{P(t), q(t), t\}$ will in both cases asymptotically converge to the equilibrium point $\left(P_{2}, q_{2}\right)$ since $f_{P}\left(P_{2}, q_{2}\right)<0$ and $4 f_{q}\left(P_{2}, q_{2}\right) q_{2}\left(1-q_{2}\right) \tau^{\prime}\left(P_{2}\right)<0$.

The final candidate is $\left(P_{3}, q_{3}\right)$. The Jacobian of this candidate is

$$
\left.\mathcal{J}\right|_{\left(P_{3}, q_{3}\right)}=\left[\begin{array}{cc}
1-\bar{\tau} & 0 \\
f_{q}(\infty, 0) & f_{P}(\infty, 0)
\end{array}\right] .
$$

The two eigenvalues $\lambda_{31,32}$ can then be calculated and are given by $\lambda_{31}=1-\bar{\tau}>0$ and $\lambda_{32}=f_{P}(\infty, 0)<0$. In this case it easily verified that the differential system is instable around this critical point.

This result is somewhat different to that derived by Sethi and Somanathan [31] as well as Nyborg et al. [26] since we exclude the existence of enforcers and allow for a feedback from the environment to the dynamics of the social norm. In other words, our result is different since with low pollution there will be less intergenerational transmission of green preferences 


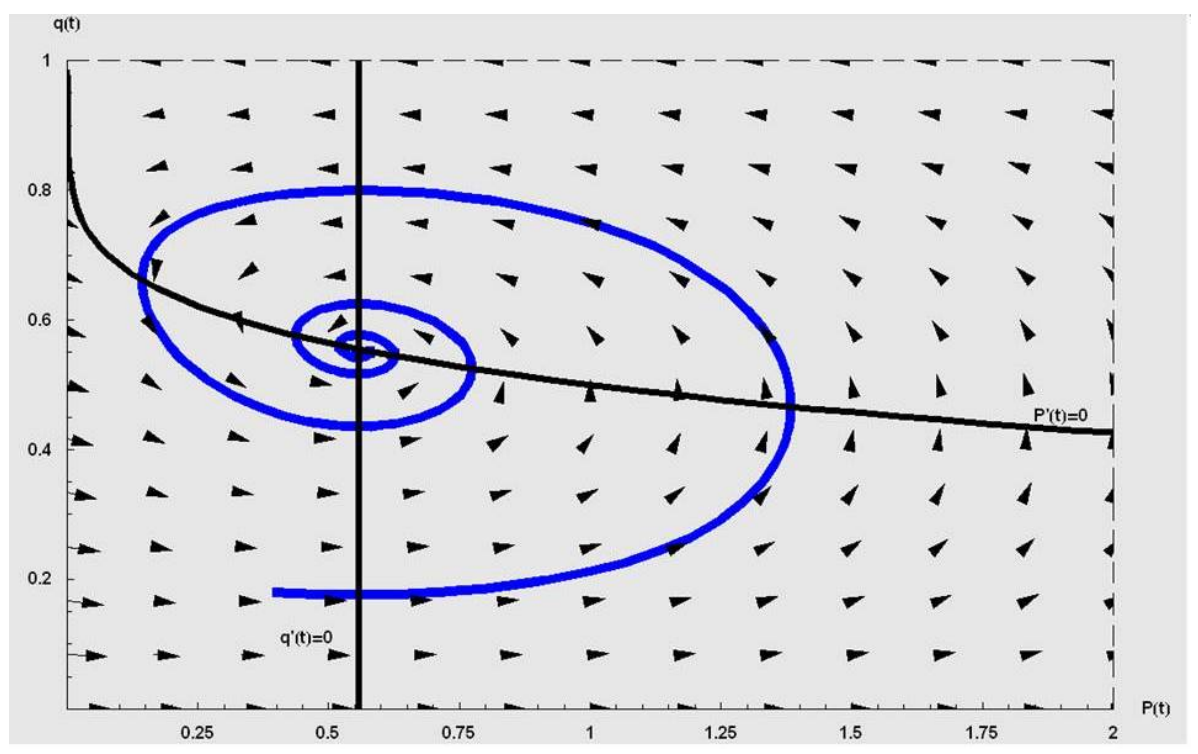

Figure 1: The dynamics of the basic model

(as there is no need for this), whereas the more pressing the environmental problems, the more people will obtain green preferences.

In Figure 1 we plot the dynamics of the system $(7)$ and (8) for initial conditions $(P(0), q(0))=$ $(0.4,0.18)$. We can easily see that the interior steady state $\left(P_{2}, q_{2}\right)$ is asymptotically stable and we approach this steady state non-monotonically. Furthermore, given that the steady state equation $0=f\left(P_{2}, q_{2}\right)$ is a continuously and monotonically decreasing function from $(P, q)=(0,1)$ to $(P, q)=(\infty, 0)$ and given that the steady state equation for $q(t)$ is independent of the level of $q(t)$, we then know that at the globally asymptotic interior steady state $\left(P_{2}, q_{2}\right)$ the level of the environment is solely fixed by $\tau\left(P_{2}\right)=\bar{\tau}$. We also find that

$$
\frac{d P_{2}}{d \bar{\tau}}=\frac{1}{\tau^{\prime}\left(P_{2}\right)}>0
$$

which thus implies that the more likely the brown preferences are adopted the higher the steady state pollution level.

\subsubsection{A discussion}

An important lesson to take away from the analysis thus far is that is that if one believes that behavior and pollution are related in the manner as described above, then standard statistical approaches may fail to detect this relationship for two reasons. Firstly, environmental attitude or behavior (more loosely, the willingness to pay) will not change linearly 
with the environmental quality over time. As one can see in Figure 1, one single pollution level may be associated with several proportions of environmentalists in society. Secondly, this also implies that it becomes difficult to do cross-country comparisons since two countries could be at a different stage of cultural evolutions - one may be at a currently high level of environmentalism and another may be at a low level of environmentalism, though both may have the same level of pollution. This suggests that history matters when one studies the relationship between environmental activity and pollution and it becomes difficult to predict future pollution levels simply based on environmental consciousness or behavior.

The relationship forwarded here is one based on a positive cultural evolution. We suggest positive because it stands in contrast to the generally forwarded Tragedy of the Commons (Hardin [18]). The Tragedy of the Commons is a standard result if one applies the concept of the self-centered, myopic individualistic utility maximization. The utilitarian justification for a shepherd who adds one sheep to the pasture is that it will increase the shepherd's return, an argument that ultimately leads to the overgrazing of the pasture. However, Hardin also suggests that "the morality of an act is a function of the state of the system at the time it is performed". We then go one step further and suggest that the morality is determined by the state of the system (here pollution) but that the morality may vice versa affect the state of the system. Elinor Ostrom [28] has worked on this extensively and suggests that, among other factors, a good social network and social norms lead to a successful management of the environment. Based on the results presented here one would believe that social coordination may often endogenously evolve in order to prevent environmental degradation.

Though we do observe this cyclical relationship between attitude or behavior and the state of the environment for some environmental systems (see footnote 2), it is also true that there are more complex forces affecting the intrinsic relationship forwarded here. These additional factors may result in dynamics that lead to different implications than drawn above. We shall now provide two relevant extensions to the relationship described in the basic model. One is based on technical change, the other on environmental laws.

\subsection{Implications of technical change}

We assume here that a technical change may exist which, for a given amount of consumption, leads to lower emissions over time. This is the case for most transportation means (like 
cars and buses), but also for electrical devices. This type of technical change is generally referred to as pollution-saving technical change (see e.g. Bovenberg and Smulders [7]). For visualization purposes we now take a separable function $f(P(t), q(t), t) \equiv g(P(t))+h(q) A(t)$, where $g(P(t)) \leq 0$ and $h(q)>0$ with $h^{\prime}(q)<0$ and $\lim _{q \rightarrow 0} h(q)<\infty$. We then assume that there exists exogenous technical change ${ }^{12}$ characterized by $A(t)$, where $A(0) \in(0,1]$ and $A^{\prime}(t) \leq 0$. One can assume that technical change is so powerful that $\lim _{t \rightarrow \infty} A(t)=0$, which we shall refer to as strong $T C$, or one may assume that there exist limits to technical change such that $A(0)>\lim _{t \rightarrow \infty} A(t) \equiv A_{\infty}>0$, referred to as weak $T C$. Then the dynamic system becomes

$$
\begin{aligned}
\dot{q}(t) & =q(t)(1-q(t))(\tau(P(t))-\bar{\tau}), \\
\dot{P}(t) & =g(P(t))+h(q) A(t) .
\end{aligned}
$$

We summarize the results in the following proposition.

Proposition 2 Based on the system (9) and (10) we find that under strong technical change, environmentalism will vanish as a cultural trait and pollution will disappear. However, under weak technical change, assume $\exists \hat{P}$ s.th. $\forall P \geq \hat{P}, \lim _{q \rightarrow 0} f(P, q) \leq 0$. If $\hat{P} \geq(\tau)^{-1}(\bar{\tau})$ then weak technical change has no effect on the steady state proportion of preferences and neither on the level of pollution. For $\hat{P}<\left(\tau^{-1}\right)(\bar{\tau})$, weak technical change reduces pollution relative to the case without technical change.

Proof 2 We use a second-order Taylor expansion around the null solution. For the system $\dot{X}=F(X)$, this looks like $\dot{X}=M(t) X+N(t)$. Two conditions are important such that the linearized system is a good enough approximation for the non-linear one. Firstly, the linearized system is quasi-autonomous, meaning the non-autonomous part does not drive the primary movements in the limit. This is equivalent to having $\lim _{t \rightarrow \infty} M(t)=M$. Secondly, the linearized system must be a uniformly good approximation for the non-linear system, which is the case if all the higher orders of the Taylor expansion vanish faster than the system approaches its critical points. This is equivalent to having $\lim _{X \rightarrow 0} \frac{\|N(t)\|}{\|X\|}=0$ (see Krasovskii [22]). We then define the null solution as $P(t)=\bar{P}+P^{*}$ and $q(t)=\bar{q}+q^{*}$, where $\left(P^{*}, q^{*}\right)$ is one of the three critical points. We thus obtain, making use of the notation above, that

\footnotetext{
${ }^{12}$ One could make the strength of technical change be dependent on the level of pollution, but this would not change the results qualitatively.
} 


$$
\left.M(t)\right|_{\left\{P^{*}, q^{*}\right\}}=\left[\begin{array}{cc}
\left(1-2 q^{*}\right)\left(\tau\left(P^{*}\right)-\bar{\tau}\right) & q^{*}\left(1-q^{*}\right) \tau^{\prime}\left(P^{*}\right) \\
h^{\prime}\left(q^{*}\right) A(t) & g^{\prime}\left(P^{*}\right)
\end{array}\right]
$$

and

$$
\left.N(t)\right|_{\left\{P^{*}, q^{*}\right\}}=\frac{1}{2}\left[\begin{array}{c}
-2\left(\tau\left(P^{*}\right)-\bar{\tau}\right) \bar{q}^{2}+2\left(1-2 q^{*}\right) \tau^{\prime}\left(P^{*}\right) \bar{q} \bar{P}+q^{*}\left(1-q^{*}\right) \tau^{\prime \prime}\left(P^{*}\right) \bar{P}^{2} \\
h^{\prime \prime}\left(q^{*}\right) A(t) \bar{q}^{2}+g^{\prime \prime}\left(P^{*}\right) \bar{P}^{2}
\end{array}\right] .
$$

We can easily observe that $\lim _{t \rightarrow \infty} M(t)=M$ in both of our cases. Therefore, our system is quasi-autonomous. In addition, we need to check whether the first-order expansion is a uniformly good approximation for the non-linear system. Since $\left\|\lim _{q \rightarrow 0, P \rightarrow 0} N(t)\right\|<\infty$, then by l'Hopital we can see that the linearized system is a uniformly good approximation for the original system.

Looking now into the two cases, then for strong TC with $\lim _{t \rightarrow \infty} A(t)=0$ we know when $t \rightarrow \infty$, we have $\dot{P}(t)=g(P(t))$. Since $g(\cdot)<0$, we know that in this case $\lim _{t \rightarrow \infty} P(t)=0$. By the evolution of equation (9) we then equivalently obtain that $\lim _{t \rightarrow \infty} q(t)=0$. Therefore, the three critical points of the model without technical change collapse into two possible critical points at $\left(P_{1}, q_{1}\right)=(0,0)$ and $\left(P_{2}, q_{2}\right)=(0,1)$. We obtain that $\left(P_{1}, q_{1}\right)$ is globally asymptotically stable whereas $\left(P_{2}, q_{2}\right)$ is unstable. With this type of technical change in place we therefore expect that environmentalism will vanish over time as a cultural trait.

On the other hand, in weak TC with $\lim _{t \rightarrow \infty} A(t)=A_{\infty}$ we know that when $t \rightarrow \infty$, we have that $\dot{P}(t)=g(P(t))+h(q) A_{\infty}$. We may now safely assume that condition (1) of Assumption 2 is no longer satisfied and especially that $\exists \hat{P}$ such that $\forall P \geq \hat{P}, \lim _{q \rightarrow 0} f(P, q) \leq$ 0. This implies an upper bound on pollution. The important point now is whether this upper bound on pollution is at a level where $\hat{P} \geq\left(\tau^{-1}\right)(\bar{\tau})$, or not. If $\hat{P} \geq\left(\tau^{-1}\right)(\bar{\tau})$ then the steady state pollution level is going to be the same as without technical change. Furthermore, the dynamics in the limit are the same as those in the system without technical change. The only change will be that there will be fewer environmentalists in the steady state. Finally, if $\hat{P}<\left(\tau^{-1}\right)(\bar{\tau})$ then the steady state level of pollution will be lower than without technical change.

The condition that $\exists \hat{P}$, such that $\forall P \geq \hat{P}, \lim _{q \rightarrow 0} f(P, q) \leq 0$ implies an upper bound on pollution, meaning that brown preferences still have an effect on the steady state level of pollution but not any longer such a disastrous one. We plot the transition for system (9) to (10) in Figure 2 with condition $\hat{P}<\left(\tau^{-1}\right)(\bar{\tau})$. The vector field shown in Figure 2 is the one 
that obtains in the limit when $t \rightarrow \infty$. Here we start at the same initial condition as in Figure

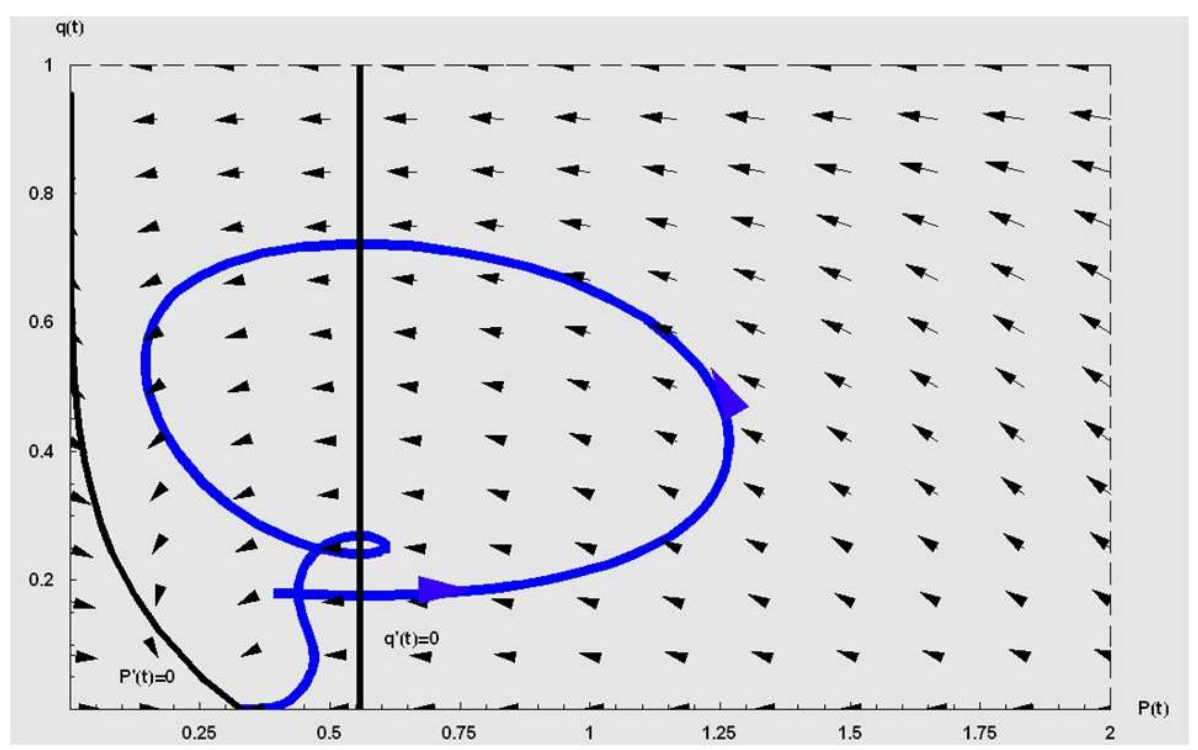

Figure 2: The dynamics with technical change

1. The evolution during the first few time intervals is the same as in the basic model since technical change evolves, at the beginning, only slowly. With increasing technical change we see, however, that the evolution of $P(t)$ and $q(t)$ change and they tend non-monotonically towards their new steady state. Since technical change in this scenario is able to sufficiently decouple consumption activity from the evolution of pollution we see that when technology has reached a certain level then the overall proportion of environmentalists does not play a significant role any more in the determination of the level of pollution. Thus, pollution will tend towards a low level and the proportion of environmentalists will tend to zero.

\subsubsection{A discussion}

A standard result in the technical change and pollution literature is that technical change is always helpful for the environment and the steady state level of pollution is reduced if we allow for technical change. Here, however, we find that technical change might not result in a lower steady state pollution level. How does this difference arise?

In the standard approaches we usually assume that technical change weakens the link between production and pollution. A given unit of production will, with improvements in technology, induce a decreasing output of pollution. Pollution-saving technical change then 
always leads to a lower steady state pollution level. (see e.g. Bovenberg and Smulders [7], Nordhaus [25])

In our case this may not hold true. Obviously, if technical change is so powerful that it is able to completely separate human activity from the evolution of pollution (our strong TC), then the result is trivial even in our problem.

However, if we take the more pessimistic, and maybe more realistic, point of view that technical change may be powerful, but not powerful enough to completely annihilate the impact of human behavior on pollution ${ }^{13}$ (our weak TC) then we find that the cultural attitude may still be the significant determinant for the steady state pollution level. Assume that human behavior bears a sufficiently strong impact on pollution that it has the ability to drive pollution to a high level. Then the steady state level of pollution will be decided by the proportion of environmentalists in the society. This happens since for an interior critical point the steady state proportion of environmentalists is given by $\hat{P}=\left(\tau^{-1}\right)(\bar{\tau})$, which is independent of the level of $q(t)$. The shape of $\tau(P)$ and the exogenously given probability $\bar{\tau}$ which is descriptive for the probability of becoming brown are then the sole determinants of the steady state level of pollution. ${ }^{14}$ In other words, if few environmentalists walk the streets, then pollution will increase. The more pollution increases, the more people will adopt the environmental social norm and therefore less browns exist and pollution will decrease. It is this cycle which leads to an interior steady state which is independent of technical change if technical change cannot alter the polluting impact of the browns by a sufficient degree. This would be the case if $\hat{P}<\left(\tau^{-1}\right)(\bar{\tau})$, meaning that technical change leads to a maximum level of pollution which is so low that even increases in browns will not increase it above that level. This would, for example, require a sufficiently strong self-regeneration rate.

We want to show, with the next example, that cultural attitude may be able to neglect substantial environmental gains from technical change. In the United Kingdom, in 1996 (resp. 2002), there were 140,286 (resp. 209,246) new registrations of petroleum-fueled cars

\footnotetext{
${ }^{13}$ By looking at e.g. the Living Planet Index, a measure of global biodiversity, we see a $30 \%$ decline in the index since 1970. Even the limited goal of the Convention on Biological Diversity (the reduction of the rate of global biodiversity loss by 2010) is unattainable. This should put the strength of technical change into perspective.

${ }^{14}$ This has a close analogy to the Ramsey model where the steady state level of consumption is independent of consumption itself and the steady state capital stock can be derived from the consumption equation.
} 
exceeding 2000cc, and 749,962 (resp. 859,205) new registrations of cars with less than 1,400cc (source: Eurostat). This means the ratio of new registrations of cars with less than 1.4 liters cylinder capacity to those with an excess of 2 liters was 5.3 in 1996 versus 4.1 in 2002 . Due to the speed limit of $112 \mathrm{~km} / \mathrm{h}$ on UK highways, a car with high cylinder capacity does not provide a speed advantage over one with less cylinder capacity. In addition, the cars with a lower cylinder capacity are generally cheaper to buy, cheaper to register, cheaper to repair, have lower annual tax costs and use less petrol. If we then interpret those cars with a lower cylinder capacity as the environmentally more advanced cars, then we notice that technical change does not, by itself, lead to a better state of the environment. What one needs is a certain attitude towards the environment that induces one to buy environmentally-friendly cars. What is even more important is that this attitude needs to overcompensate the status idea or 'ignorance' of the Browns ${ }^{15}$. Conclusively, the proportion of preferences that include environmental aspects is more important than the existence of green technologies.

\subsection{Implication of environmental standards}

We know that environmental laws are generally introduced since several types of pollution are viewed as a public problem. For example, one conclusion in the Special Eurobarometer 217 report of 2005 is that a majority of European citizens believe that environmental problems are most effectively solved at the national or international level through stricter regulations and better enforcements. These regulations should then certainly augment the intuitive relationship between environmentalism and the environment. We therefore here assume that the environmentalists can now impose environmental standards which are proportionately strong to the share of the environmentalists in the society. A law of motion which is able to capture the primitive characteristics of this assumption is

$$
\dot{s}(t)=\max \{\dot{q}(t), 0\}
$$

Thus, whenever the share of the environmentalists exceeds that of the previous moment, then the environmentalists are able to impose a tighter standard. For simplicity we assume that

\footnotetext{
${ }^{15}$ There exists some empirical evidence for environmental attitude versus status-seeking, see e.g. Choo and Mokhtarian [13]; Bhat et al [3]. There are several aspects that are neglected in the argument above. Bigger cars provide more functionality; for example, they may shift more recreational equipment. Furthermore, as White [37] argues, American consumers tend to buy sport utility vehicles simply because they are safer.
} 
this standard is equivalent to the actions which the society at that time would be willing to undertake itself. The dynamic system is then given by

$$
\begin{aligned}
\dot{q}(t) & =q(t)(1-q(t))(\tau(P(t))-\bar{\tau}), \\
\dot{P}(t) & =f(P(t), s(t)), \\
\dot{s}(t) & =\max \{\dot{q}(t), 0\}
\end{aligned}
$$

with initial conditions $q(0)=s(0)>0, P(0)>0$.

Proposition 3 If environmental laws or standards are introduced with sufficiently strong public support, then this will lead to a virtually pollution-free environment.

It is possible to split the transition path into, at maximum, three consecutive periods, depending on the initial conditions. We denote these periods as lasting from $0 \rightarrow t_{1} \rightarrow t_{2} \rightarrow t_{3}$. These time intervals can also be seen on Figures 3 and 4 . Assume that for $t=0$, we have initial conditions such that $\tau(P(0))<\bar{\tau}$ and $f(P(0), s(0))>0$. We thus start with few environmentalists, who in decreasing numbers have to fight a worsening environment. Since the environment continues to deteriorate, this motivates more and more people to start worrying and to adopt an environmentalist attitude. The phase where environmentalists increase in numbers lasts then from $t_{1} \rightarrow t_{2}$. They produce laws that lead to an overall improvement in the environment. Once pollution has declined to a 'safe' level the environmentalists notice that society has no longer any use for their attitude and they thus return to being browns. The laws that they helped to establish prove to be sufficiently strong that pollution decreases to such a level that it becomes virtually extinct, which starts the steady state period from $t_{3}$ onwards.

This result may be rather intuitive, but it must be viewed in combination with the previous results. We have shown above that the dynamic interaction between environmentalism and the environment implies an interior steady state. The only way this could be changed is if one is able to decouple social norms from the environment. Environmental laws provide exactly this possibility to break the cycle. 


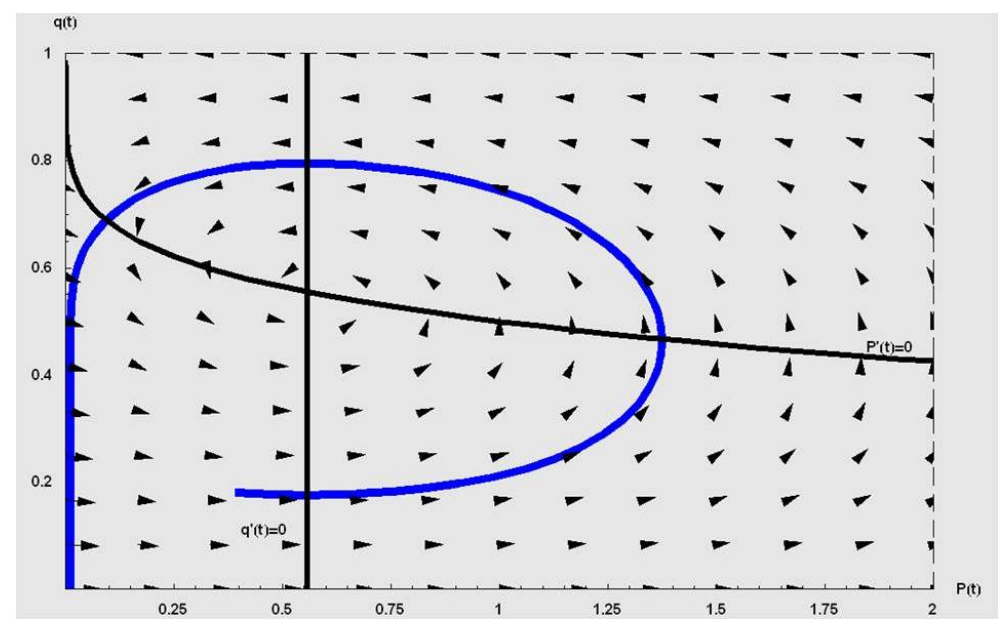

Figure 3: The dynamics with environmental standards
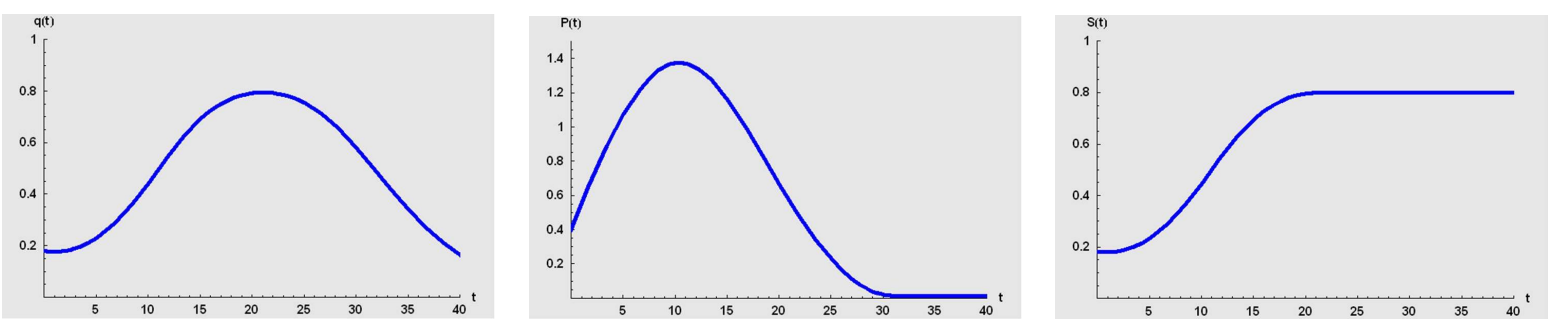

Figure 4: The dynamics of respectively $q(t), P(t)$ and $s(t)$

\subsubsection{A discussion}

When looking at data on environmental opinion, protest movements and environmental laws passed $^{16}$, one may notice a couple of intriguing results. Firstly, there is no statistically significant correlation between the number of environmental laws that have passed in a specific year and the public opinion towards the environment in the previous one. However, there is a statistically significant correlation between the number of environmental laws that have passed and the environmental movements and protests $(\rho=0.4$ with Prob $>|t|=0.0115)$. Stretching the empirical results somewhat, this suggests that an active social movement may be more important than public opinion in determining whether environmental laws get established or not. Though public opinion is certainly related to social movement, it is definitely not the same. This is also one of the fundamental conclusions advocated by Ellis and Thompson [15]. It is also this which is difficult to reconcile with a standard neoclassical, utilitarian approach.

\footnotetext{
${ }^{16}$ Here I am grateful to Jon Agnone for providing me kindly with the relevant data. See also his article Agnone [1].
} 
An important conclusion from many experimental studies is that regulation is able to crowd-out socially-oriented behavior. For example, Cardenas et al. [12], in a field experiment in Colombia, find that environmental regulations crowd out other-regarding behavior. A theoretical article that also makes this point is Brekke et al [9]. Within our model, environmental laws do not crowd out the individual actions but instead the change in the level of pollution becomes sufficiently decoupled from the preferences themselves, at least once environmental laws have been imposed to a sufficiently high level. When that level is reached, then whatever the proportion of environmentalists, the law only allows for a certain maximum level of pollutive activity. Due to the improving level of the environment, the proportion of environmentalists in society is diminishing, which might seem like a crowding-out effect, but which in reality is due to the feedback from the level of pollution to the probability of becoming an environmentalist.

It is clear that several basic conditions need to be fulfilled here. Firstly, the laws must be based on a well-defined system of property rights. Secondly, there should be little uncertainty on the polluting output and the actions of the agents. Thirdly, one could easily imagine that too stringent environmental laws are likely to lead to moral hazard actions. Therefore, a good monitoring and sanctioning system should be in place. Fourthly, the costs of the environmental standards are not included. If the costs are too high then people will obviously try to find ways in which they could circumvent the law. Finally, the laws must be, to a certain extend, ultimate, meaning that even though it seems the laws are not useful any longer (e.g. if pollution is very low), it must not be possible to revert the law. It seems critical that these conditions are in place in order to obtain the result of proposition 3 . If several of the conditions are not in place, then the market-based instruments in Brekke et al. [9] are likely to fare better.

\section{Conclusion}

In this article we propose a basic relationship between a mechanism of cultural dynamics, taken from Bisin and Verdier ([4], [5]), and the environment. We suggest that a higher pollution level leads to a higher probability of becoming an environmentalist, and sufficiently many environmentalists imply an improvement in environmental quality. We use data and field studies to support the basic workings of this mechanism. Within this framework we 
find that there exists a globally asymptotic interior steady state. Convergence to this steady state is, however, non-monotonic. If one then believes this basic dynamical relationship, then this suggests that standard statistical approaches may fail to detect it due to the nonmonotonic relationship between attitudes or behavior and pollution. Also, cross-sectional analyzes might fail since one level of pollution might be associated with several proportions of environmentalists.

We then analyze the effects of technical change and environmental laws. Firstly, technical change that is strong enough to completely decouple consumption behavior from pollution leads to the straight-forward result of no environmentalists in the steady state and no pollution. Taking the more realistic assumption of weaker technical change, we find that technical change - contrary to standard results - might not lead to any change in the steady state level of pollution. We also provide an example where the level of pollution is driven by the proportion of preferences which include environmental aspects instead of the existence of affordable green technologies.

Secondly, when we introduce environmental laws (with adequate property rights and supervision system in place), we find that they may lead to a virtually pollution-free environment. This will be the case for environmental laws that are put in place with sufficient public support. We also discuss the driving factors behind environmental laws and notice, in accordance to findings in other disciplines, that laws do not get established simply because people's attitude is green. We notice that social movements are the main driving forces behind the number of environmental laws that pass. One further result is that there is a 'good' time for the introduction of environmental laws, implying a discrepancy between attitude (here public opinion) and behavior (here social movement). This is when public support is the greatest in order to implement the tightest laws that seem reasonable at that time. Laws require public support and latest since Malthus, the 'Limits to growth' or 'An inconvenient truth' should we know that informing people is only part of the game. One then has to ride the wave of public support to break the ice between future generations and ourselves, between what we are willing to do today and what we might be willing to do when other times leave us fewer options.

The basic dynamic relationship forwarded here opens up a number of unanswered and difficult questions. Firstly, if environmental preferences are a fluid concept, as proposed here, 
then how should we evaluate the welfare impacts over time? Indeed, how do we define welfare? One possible solution is to look at concepts like weak and strong sustainability, but these may need to leave aside a standard welfare evaluation based on utilitarian terms.

Secondly, this article only looks into one part of the story, namely where preferences form in a direction that is helpful for the state of the environment. This requires, however, a certain degree of either collective action that persists in the society, or a sufficient degree of individual responsibility. One conclusion of the Special Eurobarometer 217 report is that over $85 \%$ of European citizens claim to sometimes or often make an effort to protect the environment. Thus, action is undertaken at the individual level ${ }^{17}$, especially when it is directed to local environmental problems. We also see, however, that the Tragedy of the Commons is likely to occur in several social contexts. One of these contexts should be a highly segregated society with few interactions. In that case one should analyze endogenous bounds on the social dynamics of environmentalism. If one for example assumes that society is so segregated that environmentalists only talk to environmentalists, then this will eliminate the critical point with $(P, q)=(0,1)$. One can obviously generalize these cultural dynamics in many ways.

Finally, the results obtained here rely heavily on the assumption that environmentalists have a sufficiently high budget to act 'green'. This, indeed, may not be the case and income might play a crucial role, too. Though there is sufficient evidence that an environmentallyfriendly behavior is possible even without large financial resources ${ }^{18}$, it is a common assumption in economics that a trade-off is bound to be found somewhere. A future extension of this work could then look at the trade-off between educational expenditures on environmentalism and the relative efficiency of abatement activity.

\section{Appendix}

\subsection{A possible choice mechanism}

A possible choice mechanism could be as follows. Agents maximize their concave utility of consumption $u(c)$, which is equal to wages minus green effort $w-e . I_{g}$ is an indicator function which takes $I_{g}=1$ for someone with green preferences and $I_{g}=0$ for someone with brown

\footnotetext{
${ }^{17}$ Although these citizens at the same time feel that their effort are futile.

${ }^{18}$ Clearly, people with larger financial resources also have a bigger ecological footprint since they usually have a bigger house and travel more than poorer people.
} 
preferences. Deviations from the social norm of acting green is a utility loss, which we denote by the convex function $v\left(e-e^{*}\right)$, where $v(\cdot)>0$ and $v_{e}<0$. Agents then maximize

$$
u(w-e)-v\left(e-e^{*}\right) I_{g} .
$$

At the interior optimum, agents use an effort level of $u^{\prime}(c)=v^{\prime}\left(e-e^{*}\right) I_{g}$, with $e=0$ for $I_{g}=0$. Thus, agents with brown preferences completely neglect the social norm of acting green and therefore provide no effort, whereas green agents provide a positive, constant effort. Obviously, this choice mechanism provides a constant effort level only if there are no substantial changes in income and if agents cannot impact pollution for other reasons than the social norm.

\subsection{The equations used in the plots}

Here we provide the functional forms of the equations used in plotting the Figures in the article. The plots were done in Mathematica and the notebook file is freely available from the author. For the part of the fundamental relationship we plotted

$$
\begin{aligned}
\dot{q}(t) & =q(t)(1-q(t))(1-\exp [-0.4 P(t)]-0.2) \\
\dot{P}(t) & =0.4\left(-0.5 P(t)^{0.2}+(1-q(t))\right)
\end{aligned}
$$

For the part of technical change we assume

$$
\begin{aligned}
\dot{q}(t) & =q(t)(1-q(t))(1-\exp [-0.4 P(t)]-0.2) \\
\dot{P}(t) & =0.4\left(-0.5 P(t)^{0.2}+(1-q(t))(0.6 \exp [-0.02 t]-0.4)\right) .
\end{aligned}
$$

For the vector field we only plotted the dynamics which obtain in the limit when $t \rightarrow \infty$.

The environmental law system is based on the three equations

$$
\begin{aligned}
\dot{q}(t) & =q(t)(1-q(t))(1-\exp [-0.4 P(t)]-0.2) \\
\dot{s}(t) & =\max \{q(t)(1-q(t))(1-\exp [-0.4 P(t)]-0.2), 0\} \\
\dot{P}(t) & =0.4\left(-0.5 P(t)^{0.2}+(1-s(t))\right)
\end{aligned}
$$

\section{References}

[1] J. Agnone. Amplifying Public Opinion: The Policy Impact of the US Environmental Movement. Social Forces, 85(4):1593, 2007. 
[2] G.S. Becker and C.B. Mulligan. The Endogenous Determination of Time Preference. Quarterly Journal of Economics, 112(3):729-758, 1997.

[3] C.R. Bhat, S. Sen, and N. Eluru. The impact of demographics, built environment attributes, vehicle characteristics, and gasoline prices on household vehicle holdings and use. Transportation Research Part B, 43(1):1-18, 2009.

[4] A. Bisin and T. Verdier. On the cultural transmission of preferences for social status. Journal of Public Economics, 70(1):75-97, 1998.

[5] A. Bisin and T. Verdier. The Economics of Cultural Transmission and the Dynamics of Preferences. Journal of Economic Theory, 97(2):298-319, 2001.

[6] R. Bord and R. O'Connor. The gender gap in environmental attitudes: The case of perceived vulnerability to risk: Research on the environment. Social Science Quarterly, 78(4):830-840, 1997.

[7] A. Bovenberg and S. Smulders. Environmental quality and pollution-augmenting technological change in a two-sector endogenous growth model. Journal of Public Economics, 57(3):369-391, 1995.

[8] S. Bowles. Endogenous Preferences: The Cultural Consequences of Markets and Other Economic Institutions. Journal of Economic Literature, 36:75-111, 1998.

[9] K.A. Brekke, S. Kverndokk, and K. Nyborg. An economic model of moral motivation. Journal of Public Economics, 87(9-10):1967-1983, September 2003.

[10] K.M. Brown and L.O. Taylor. Do as you say, say as you do: evidence on gender differences in actual and stated contributions to public goods. Journal of Economic Behavior and Organization, 43(1):127-139, 2000.

[11] G. Buenstorf and C. Cordes. Can sustainable consumption be learned? a model of cultural evolution. Ecological Economics, 67(4):646-657, November 2008.

[12] J.C. Cardenas, J. Stranlund, and C. Willis. Local Environmental Control and Institutional Crowding-Out. World Development, 28(10):1719-1733, 2000. 
[13] S. Choo and P.L. Mokhtarian. What type of vehicle do people drive? The role of attitude and lifestyle in influencing vehicle type choice. Transportation Research Part A, 38(3):201-222, 2004.

[14] M. Dalhouse and J.S. Frideres. Intergenerational Congruency: The Role of the Family in Political Attitudes of Youth. Journal of Family Issues, 17(2):227, 1996.

[15] R. Ellis and F. Thompson. Culture and Environment in the Pacific Northwest. American Political Science Review, 91(4):885-897, 1997.

[16] L. Escriche, G. Olcina, and R. Sanchez. Gender discrimination and intergenerational transmission of preferences. Oxford Economic Papers, 56(3):485-511, 2004.

[17] C.F. Graumann and L. Kruse. The environment: Social construction and psychological problems, pages 212-229. London: Sage, 1990.

[18] G. Hardin. The Tragedy of the Commons. Science, 162(3859):1243-1248, 1968.

[19] E. Hauk and M. Saez-Marti. On the Cultural Transmission of Corruption. Journal of Economic Theory, 107(2):311-335, 2002.

[20] C.Y. Johnson, JM Bowker, and H.K. Cordell. Ethnic Variation in Environmental Belief and Behavior: An Examination of the New Ecological Paradigm in a Social Psychological Context. Environment and Behavior, 36(2):157, 2004.

[21] W. Kempton, J.S. Boster, and J.A. Hartley. Environmental Values in American Culture. MIT Press, 1995.

[22] N.N. Krasovskii. Stability of Motion: Applications of Lyapunov's Second Method to Differential Systems and Equations With Delay. Stanford Univ Pr, 1963.

[23] J. Larcombe and G. Begg. Fishery Status Reports 2007, Status of fish stocks managed by the Australian Government. Australian Government Department of Agriculture, Fisheries and Forestry Bureau of Rural Sciences, 2008.

[24] R. Linton. Acculturation in Seven American Indian Tribes. Peter Smith Pub Inc., 1963.

[25] W.D. Nordhaus. A question of balance: weighing the options on global warming policies. Yale Univ Pr, 2008. 
[26] K. Nyborg, R.B. Howarth, and K.A. Brekke. Green consumers and public policy: On socially contingent moral motivation. Resource and Energy Economics, 28(4):351-366, November 2006.

[27] E. Olli, G. Grendstad, and D. Wollebaek. Correlates of Environmental Behaviors: Bringing Back Social Context. Environment and Behavior, 33(2):181, 2001.

[28] E. Ostrom. Governing the Commons: The Evolution of Institutions for Collective Action. Cambridge University Press, 1990.

[29] W. Schultz. The structure of environmental concern: concern for self, other people and the biosphere. Journal of Environmental Psychology, 21(4):327-339, 2001.

[30] A. Sen. Internal Consistency of Choice. Econometrica, 61:495-495, 1993.

[31] R. Sethi and E. Somanathan. The evolution of social norms in common property resource use. American Economic Review, 86(4):766-88, September 1996.

[32] P. Taylor and L. Jonker. Evolutionary stable strategies and game dynamics. Mathematical Biosciences, 40(2):145156, 1978.

[33] A. Thornton and L. Young-DeMarco. Four Decades of Trends in Attitudes Toward Family Issues in the United States: The 1960s Through the 1990s. Journal of Marriage and Family, 63(4):1009-1037, 2001.

[34] B. Torgler and M.A. García-Valiñas. The determinants of individuals' attitudes towards preventing environmental damage. Ecological Economics, 63(2-3):536-552, 2007.

[35] D. Urban. Was ist Umweltbewußtsein? Exploration eines mehrdimensionalen Einstellungskonstruktes. Zeitschrift für Soziologie, 15(5):363-377, 1986.

[36] M. Villacorta, R. Koestner, and N. Lekes. Further Validation of the Motivation Toward the Environment Scale. Environment and Behavior, 35(4):486, 2003.

[37] M. White. The 'arms race' on American roads: The effect of sport utility vehicles and pickup trucks on traffic safety. Journal of Law and Economics, 47:333-355, 2004.

[38] H.P. Witzke and G. Urfei. Willingness To Pay for Environmental Protection in Germany: Coping With the Regional Dimension. Regional Studies, 35(3):207-214, 2001. 